\title{
Arthur Koestlers nevrolitterære arv
}

\section{Forfatteren Arthur Koestler er kjent for sine romaner, autobiografier} og politiske skrifter. Mindre kjent er hans bidrag til nevrolitteraturen. Han skrev utførlig om nervesystemets utvikling og om den «holistiske» oppbyggingen av sentralnervesystemet i en rekke romaner, essays og fagprosa, men også om forholdet mellom følelser og intellekt i politiske ismer og i hjernens funksjonelle interaksjon mellom emosjon og intellekt.

Arthur Koestler (1905-83) (fig 1) ble født i 1905 i Budapest. I 1926 dro han til Palestina der han ble Midtøsten-korrespondent for Ullstein-konsernet i Berlin (1). Han var en produktiv journalist og essayist. På grunn av sin evne til å popularisere naturvitenskapelige emner ble han i 1930 naturvitenskapelig redaktør i Ullstein. I 1931 var han med på grev Zeppelins ferd til Nordpolen som skribent, og i desember meldte han seg inn i det tyske kommunistiske parti.

Koestler reiste til Sovjetunionen 1932-33 og skrev om livet der. Han forble kommunist til 1938, men den selvopplevde hungersnøden i Ukraina ble en tidlig øvelse i bortforklaring. I 1933 forlot han Sovjet og dro til Paris, som ble hans hovedbase til høsten 1936. Han levde av pennen og strøjobber, bl.a. som lærer i forstaden Maisons Lafitte, der han ble vitne til en difteriepidemi. Som medgrunnlegger av Institut pour l'étude du fascisme (INFA) møtte han mange spen- nende personer, inkludert André Malraux, hvis Tourettes syndrom han senere beskrev i selvbiografien Den usynlige skrift (2).

I 1936 ble Koestler korrespondent for London-avisen News Chronicle. Komintern ønsket at han skulle undersøke tysk og italiensk intervensjon på Francos side, ved hovedkvarteret i Sevilla (2, 3). I Sevilla traff han August Strindbergs sønn, en tidligere kollega fra Berlin, som var korrespondent for et nazifisert Ullstein. Dette gjorde at han måtte flykte raskt via Gibraltar. Fra London kom han til Madrid, der han skulle involvering på Francos side i borgerkrigen. Han møtte Gerda Grepp, Arbeiderbladets korrespondent, og de reiste sammen til Malaga i januar 1937. Der ble han arrestert og måtte sitte i delvis isolat (3). Under fengselsoppholdet funderer han over totalitære systemers dynamikk. Det ble en siste råtnende planke $\mathrm{i}$ hans kommunistiske hus. sikre og oversette dokumenter om tysk

\author{
Bernt A. Engelsen \\ bernt.engelsen@helse-bergen.no \\ Nevrologisk avdeling \\ Haukeland universitetssykehus \\ 5021 Bergen \\ og \\ Institutt for klinisk medisin \\ seksjon for nevrologi \\ Universitetet i Bergen
}

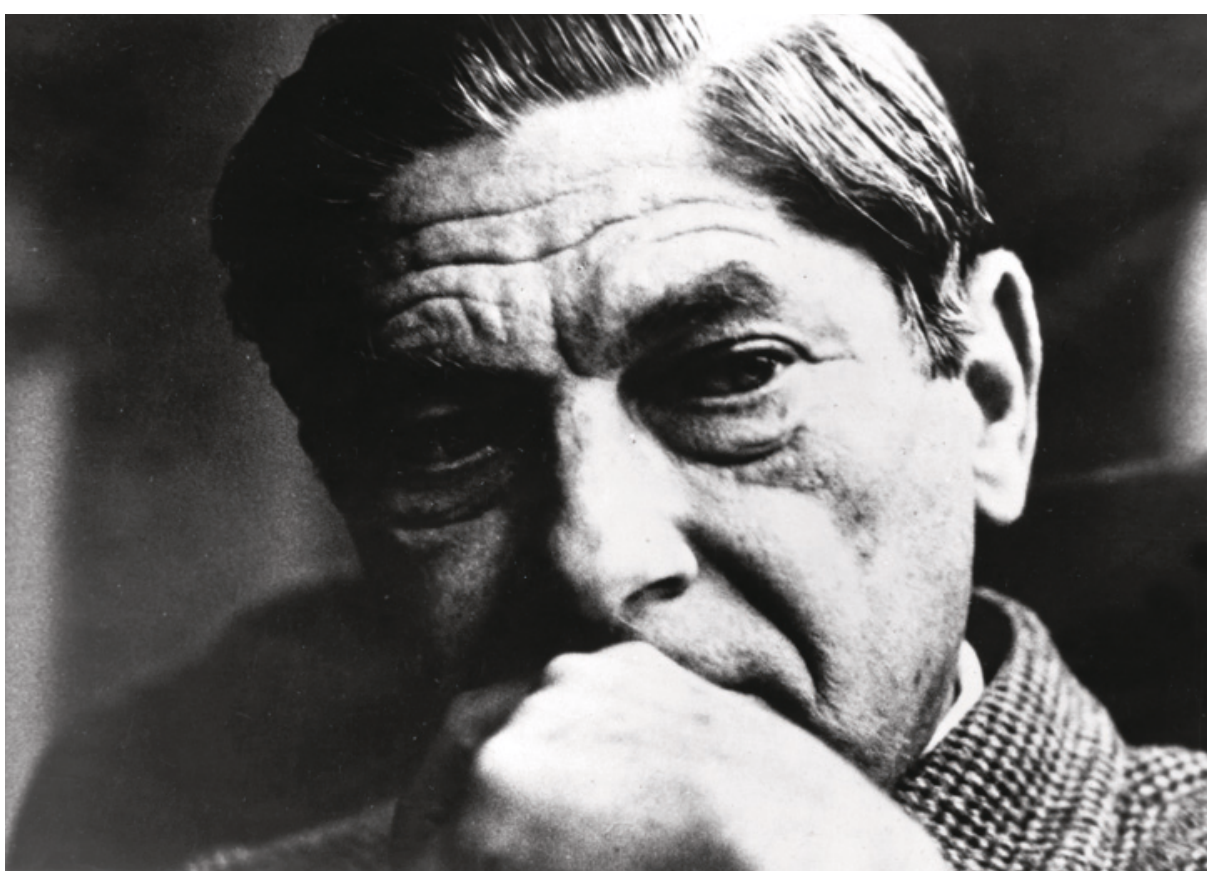

Figur 1 Arthur Koestler. Foto The Granger Collection/NTB scanpix 
Engelske venner sørget for at han slapp fri fra dødsdom og fengsel, og han returnerte til Paris. Der ble han fengslet i 1939 og internert i leiren Vernet, som han beskriver i Jordens berme (4). Etter frigivelsen kom han via Oran og Lisboa (beskrevet i Ankomst og avreise (5)) til England. Han ble kortvarig internert i Pentonville-fengselet før han slo seg ned i England for godt. Romanen Mørke midt på dagen (6) ble utgitt under hans opphold i Pentonville.

Resten av livet bodde han med korte avbrekk i England med en urolig penn, et sosialt og faglig liv preget av en indre uro, et klart intellekt og en stadig søken etter «sannheter» (7) og innsikt i hjernens fysiologi.

Koestler skrev romaner, essays og selvbiografier som samtidig er interessante tidsskildringer. Han skrev også sakprosa preget av teorier om kreativitet, utviklingslære og hans personlige filosofi knyttet til struktur og utvikling av vårt nervesystem, og om hvorledes totalitære regimer og ideologier kan engasjere og fengsle den menneskelige hjerne. I mange av bøkene refererte han til tidens nevrobiologiske forskning.

\section{Litteraturutvalg}

Undertegnede har lest igjennom Arthur Koestlers bøker. De fleste er lest på norsk, noen på engelsk og tre av bøkene er lest på tysk. De respektive bøkene er angitt i e-tabell 1 og delt inn i fire tematiske grupper (1-6, 8-23). Disse bøkene er utgangspunkt for en oppsummerende diskusjon rundt det jeg opplever som hans nevropsykobiologiske litterære arv og som fortjener å ses i et medisinskhistorisk perspektiv. Kun bøker som i sin helhet er skrevet av Koestler er inkludert, og bøker uten nevropsykobiologiske referanser er ikke omtalt. For en fullstendig oversikt over Koestlers bøker vises det til Scammels biografi (7).

\section{Essays og romaner før 1960}

I Et spansk testament (3), skrevet på tysk, forteller han om sitt opphold og fengsling i Spania i 1936-37.

I Mørke midt på dagen (Darkness at noon) (6), som utkom i desember 1940 treffer vi den kommunistiske fiktive personen Nikolai Salmanovitsj Rubasjov. Han fengsles og dissekerer sitt politiske virke retrospektivt. Revolusjonshelten og nære medarbeider av Nr. 1 lider en ublid skjebne i det som synes å være tredje runde av Moskvaprosessene. Dette regnes som forfatterens viktigste roman og internasjo- nale gjennombrudd, og her starter han sin litterære søken etter ondskapens cerebrale substrat.

I boken Ankomst og avreise (5) fra 1943 møter vi 22-årige Peter Slavek som er revolusjonær, har sittet i fengsel og er blitt torturert. Slavek får innvilget visum til England, men høyrebeinet svikter og han får en hysterisk lammelse. Lammelsen behandles av dr. Sonja Bolgar gjennom psykoanalyse, som sannsynligvis ikke er helt vellykket (fig 2) (8). I Strangers on the square (fig 3) (9) skriver Koestler at personen Peter Slavek er basert på hans ungarske venn og landsmann, Endre Havas, som døde etter langvarig tortur i fengsel i Ungarn i 1952/53. Men Slavek har også autobiografiske trekk (7).

I Yogien og kommissaren (10) presenteres essays om sosial- og individpsykologi, samfunnsdebatt, inkludert den økonomiske og politiske utviklingen i Sovjetunionen, refleksjoner rundt kunst, forfattere, bokanmeldelser og om folkets tvil om grusomhetene under den annen verdenskrig. I avsnittet «En mytes anatomi» (1943) tar han for seg menneskesinnets schizofrene tilbøyeligheter: «Den viktigste forskjellen mellom patologisk og normal schizofreni ligger $i$ at den irrasjonelle komponent i den første er isolert, mens ufornuften i det siste tilfellet blir kollektivt godtatt.» Han viser til at hjerneforsøk på dyr og undersøkelser av krigsskadede fra forrige verdenskrig har avslørt to gjensidig hemmende reaksjonstendenser $i$ en gitt situasjon: «thalamusatferd» og «hjernebark atferd». Den første bestemmes av følelse, den siste av formell tenkning. Han anfører at «irrasjonell tro bunner i følelser, man føler at det er sant. Tro kan defineres som det å vite med innvollene».

Lengselens tid (11) fra 1951 er en fremtidsrettet roman der handlingen utspilles i Paris i 1950-årene, i lengselen etter eller forventningen om en bedre og mer meningsfylt tid. Her diskuteres Hegels dialektikk, religion, filosofi og livets fenomenologi. I bokavsnittet «Tretthet i synapsene» (s.177) sliter Leo Leontjev med et referat fra en tale og fikk «bråk med syntaksen». Symptomene gjenkjennes av en professor Gruber som kaller dette tretthet i synapsene, betinget av giftstoffer som lammer synapsenes virksomhet. Senere i samme kapittel heter det: «Litt justering av synapsene, noen piller og diskusjoner - og han ville avsløre for den forbausede verden at han var selveste Rasputin (s. 208).

Lotusen og roboten fra 1960 (12) er en slags fortsettelse av Yogien og kommis- sceren, der Koestler tar oss med på en reise til India og Japan. Samfunn, psykologi og mystiske sider ved yoga og zendyrkingen omhandles. I Die Nachtwandler (13) presenteres historien bak vårt heliosentriske verdensbilde, fra Herakleides til Copernicus og Kepler.

\section{Autobiografiene}

I Koestlers første selvbiografi, Jordens berme fra 1947 (4), tar han et personlig oppgjør med det franske byråkratiets rolle i 1939-40 og egne erfaringer i interneringsleiren Le Vernet. En pil i det blå (1) (1952) er hans andre selvbiografi og tar for seg litt om psykologi og om opplevelser fra barndommen. I vår setting er den semireligiøse omvendelsen til kommunismen særlig relevant og innsiktsfullt skildret. Bak dette er det formelig noe organisk. Skildringen er interessant særlig fordi begrepet «politisk religion» nylig har fått en akademisk aksept (14), og Bernt Hagtvedt refererer eksplisitt til ham i et kapittel i Ideologi og terrorisme (15).

Oppfølgeren Den usynlige skrift (1954) (2) starter med hans kommunistiske år (1931-38). Koestler forteller at han mellom de «vigslede perioder» ble deprimert og fikk selvmordsfantasier (s. 259). Senere $\mathrm{i}$ livet kunne han få avgrunner av depresjon

\section{TRYGVE BRAATOY}

ARTHUR KOESTLER OG PSYKOANALYSEN

Koestler har rørt ved kjernen i de moralske og psy kologiske problemer som er livsviktige for mennes skene i dag. Her gir psykiateren Trygve Braatøy nye og overraskende bidrag til den aktuelle debatten. J. W. CAPPELENS FORLAG

Figur 2 Faksimile fra Trygve Braatøys Arthur Koestler og Psykoanalysen 


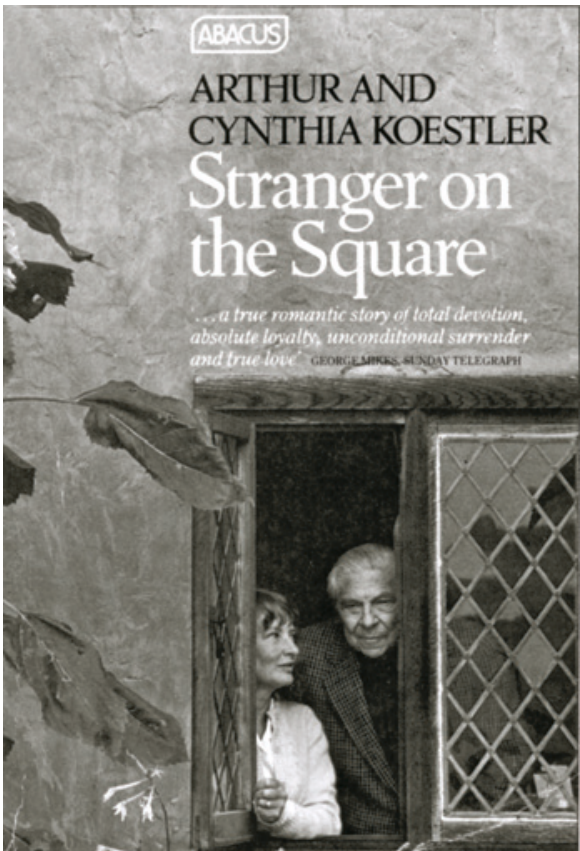

Figur 3 Faksimile fra Stranger on the square

i perioder og stilte selv diagnosen «maniskdepressiv type», men han slet med å identifisere bryterne for de enkelte fasene. Han beskriver også sin egen angstnevrose og vedgår at han av og til selvmedisinerte med vin. Paradoksalt nok var hans eneste angstfrie periode tiden han tilbrakte i fengsel (s. 322).

En siste autobiografi, Stranger on the square (fig 3), som delvis føres i pennen av hans siste kone Cynthia, ble utgitt posthumt i 1984 (9). Her forteller han om tiden etter ankomsten til England og frigivelsen fra Pentonville før jul 1940. Beskrevet er også en togtur med Jean Paul Sartre (1905-80) og et møte med en livvakt på vei til et kulturarrangement i Berlin i 1950. Livvakten advarte mot at han fikk epileptiske anfall når han ble følelsesmessig alterert (9).

\section{De nevropsykobiologiske hovedverkene}

Insight and outlook utkom i 1949 (16), og er en forløper for de to bøkene nevnt nedenfor. I første del, om det komiske, omtaler han humoren og latteren, dens former og psykologi. Han opplyste om at nevrofysiologien ville bli omtalt i bind 2 . Det ble forsinket og «erstattet» av The act of creation (17) og The ghost in the machine (18). Han skrev likevel om cortex og thalamus (inkludert hypothalamus) og interaksjonen mellom tanke og emosjon, som han utbroderte i avsnittet «The dissociation of thought and emotion» (s. 64).

Han skrev omfattende om sin teori om kreativitetens bisosiasjon, som er når to hittil urelaterte begrepsområder blir knyttet sammen til en ny idékonstruksjon. Omtalt blir også selvhevdelse (self-assertion) og selvfornektelse (self-transcendence), i denne konteksten reflekterende emosjoner knyttet til latteren, som er en sympatisk tilstand, og gråten, som er en parasympatisk tilstand. Nevrologiske årsaker til patologisk latter nevnes også. Han skriver om ekstrasensorisk persepsjon (ESP), som får fullt fokus i The roots of coincidence (19). Insight and outlook ble skrevet i Wales der han fra 1946-48 bodde og samarbeidet med George Orwell (1903-50) og Bertrand Russell (1872-1970). Sistnevnte ble av Koestler karakterisert som «strangely lacking in human warmth».

The Act of creation (17) er en bok om nettopp kreativitet og om fellesmekanismer for kunstnerisk og vitenskapelig skapelse og humor. Det dreier seg mest om psykologien, men også om nevrologien bak latter, følelser og kreativitet. Dette er en ny, forbedret versjon av Insight and outlook og er et hovedverk i Koestlers sene litterære produksjon.

The Ghost in the machine (18) er ut ifra vårt ståsted kanskje hans viktigste verk. Innledningsvis gjennomgås teorien om holon (holos $=$ hel), der endelsen -on, som i proton/nøytron, betegner en partikkel eller en del. Hypotesen er at alt liv er bygd opp av selvstendig fungerende enheter (holons) som utgjør subenheter i større hierarkier. Dette er biologiens «janusansikt», som beskrevet i boken Janus: a summing up (20). I The Ghost in the machine refereres det til mer enn biologiske hierarkier: Holistisk orden hersker i mange sammenhenger, også sosialt. Dette er et krast oppgjør med John B. Watson (1878-1958), Burrhus Frederic Skinner (1904-90) og behaviorismen med sin stimulus-respons-tenking. Koestler fremholder holistisk funksjon i hjernen som en måte å analysere alt det som ligger mellom stimulus og respons. Boken handler om menneskets hjerne, dens utvikling, holons, hukommelse, emosjoner og «the predicament of man» (= menneskets dilemma/knipe). Emosjonene får bred omtale og defineres som «...mental states accompanied by intense feeling and involving bodily changes of a widespread character» (s. 226). Alle emosjoner har en «hedonisk tone», altså grad av behag eller ubehag.

Han diskuterer ulike emosjoner og deres betydning for bl.a. kunst. Selvhevdende emosjoner innsnevrer bevissthetsfeltet, mens transcenderende følelser utvider bevissthetsfeltet, helt til selvoppløsende tendenser (såkalt «oceanic feeling», i mystikk og i f.eks. religiøs eller politisk forstand). Teorien om hjernens iboende funksjonelle defekt mener Koestler er en delforklaring på at mennesket kan forville seg på ismenes sti.

The Roots of coincidence (19) fra 1972 dreier seg om ekstrasensorisk persepsjon (ESP) og liknende fenomener. Janus: a summing up (20) er nettopp det; en oppsummering og sentrering rundt tankene som han tidligere har lansert, med noen nye kommentarer. Bricks to Babel (selected writings with author's comment) (21) er en ny summering og videreutvikling av ovennevnte bøker.

\section{Sene romaner og faglitteratur}

Der Krötenküsser (22) vies skandalen rundt biologen og lamarckisten Paul Kammerer (1880-1926) som tok sitt liv etter forskningsfusk.

Romanen The call girls (23) (1973) omhandler deltakelse $i$ et symposium, «Approaches to survival», i alpebyen Schneedorf. Dette er tydelig basert på Alpbach-symposiet som Koestler var medarrangør for i 1967, der en rekke verdenskjente nevrobiologer og filosofer deltok, inkludert vennen Paul D. MacLean (1913-2007) (24-27). Romanen viser Koestlers evne til å dramatisere erfaringer fra års arbeid med symposier og erfaringer fra arbeidet som «fellow» ved Center for Advanced Study in the Behavioral Sciences ved Stanford University (1964-65).

\section{Diskusjon}

Koestler var søkende og belest. Etter egen vurdering var han preget av angstnevrose i perioder og kan ha hatt episoder med konversjonssymptomer. Morens migrene og kontrollerende personlighet påvirket hans liv opp i voksen alder $(7,9)$. Hans selvdiagnose - manisk depressiv lidelse $(2,7,9)$ virker rimelig og preget livsførselen, den produktive skrivingen og hans brokete privatliv (7).

Fra studietiden etter møte med Sigmund Freud (1856-1939) og Carl Gustav Jung (1875-1971) i Wien, var han åpenbart interessert i den menneskelige hjerne, og han reflekterte rundt ondskapens cerebrale substrat i Mørket midt på dagen (6), skrevet 1938-40. Da hadde Papez skrevet sin artikkel om emosjoner i 1937 (28), men jeg tror ikke Koestler kjente artikkelen. Han refererte ikke til den i Insight and outlook (16), men der siterte han Bards artikkel fra 1939 (29).

I Yogien og kommisceren (10) videreutvikler han sine hypoteser fra En mytes anatomi (1943) og viser til at hjernebarken styrer formell tenking, mens thalamus (inkludert hypothalamus) er setet for følelser og sinnsbevegelser (emosjoner). Han hevder at irrasjonell tro bunner i følelser, «følt sannhet» og tro kan defineres som det å vite med innvollene. I Insight and outlook går han videre med ideene om tankenes og følelsenes fysiologi, spesielt deres plutselige dissosiasjon som del av det komiske (16, s.65). Denne boken ble skrevet før Paul D. MacLeans arbeid fra 1949 om «the visceral brain» (24). Koestler ble senere meget godt kjent med MacLeans tidlige 1950-tallsarbeider vedrørende det limbiske system $(25,26)$, og samtaler med MacLean bidro sikkert til Koestlers formulerte hypoteser i 1960-årene $(17,18)$. 
Vi kan følge Koestlers interesse for nevrologien i en rekke bøker (e-tab 1), ofte som litterære digresjoner, men med tydelige nevrobiologiske referanser i flere av essaysamlingene $(10,12)$ og som tema i romanen Lengselens tid (11).

Imidlertid er det de «senere» bøkene, The act of creation og The ghost in the machine $(17,18)$ som utgjør de nevrolitterære hovedverkene. Tematikken i disse er kreativitet, hjernefysiologi, nevrologi, psykiatri og nevropsykologi. Disse verkene fortjener fortsatt å bli lest, kanskje mest $i$ en politisk ramme rundt «det onde», totalitarisme og politisk religion $(14,15)$. Det er nok ikke tilfeldig at Hagtvedt omtaler Koestler i en nylig utgitt bok (15, s.125). Interessant nok refererte Koestler til Hannah Arendt (1906-75) og hennes tanker om personlig ansvar og nazisme (18), og hun vies stor plass i en nylig utgitt bok om terrorisme (14).

Koestler hevdet at mennesket var et uvanlig biologisk dyr og at det hadde skjedd en feil i utviklingen av nervesystemet vårt $(17,18)$. Vi har opplevd en eksplosjonsartet utvikling av neocortex, med påfølgende svekket kontroll med den emosjonelle delen av hjernen, det limbiske system $(17,18,20)$. Emosjoner opptok ham sterkt, og han mente at de hovedsakelig kunne deles i de selvhevdende og de selvfornektende/selvtranscenderende. Begge disse kunne være problematiske når de ble knyttet opp mot politiske og religiøse overbevisninger, dvs. tro, som igjen er følt sannhet.

Menneskets generelle hang til paranoia, den langvarige hjelpeløsheten hos nyfødte med påfølgende underkastelse overfor autoriteter, språkets iboende doble forbannelse samt angst for døden er tilleggsgrunner til at ondskapen kan få sitt sete i hjernen eller at ondskapen kan være en normalvariant hos vår art. Allikevel: For Koestler var forskningshistorie, humor og kreativitet like viktig som disse tankene $(13,16,17)$.

I sine siste år led Koestler av Parkinsons sykdom og leukemi. Han var aktiv motstander av dødsstraff i England og tilhenger av selvbestemt død. I mars 1983 tok han sitt eget liv, og sammen med ham tok hans siste kone også sitt liv. Hun var frisk, og mange har klandret Koestler for å ha dratt henne med i døden. Koestler var en meget omstridt herre sosialt (7) og var sikkert en krevende livspartner.

Han hadde et usedvanlig hode og engasjement og var en åpenbar inspirasjon for mange forfattere, inkludert Jens Bjørneboe (1920-76), som vedkjente seg denne arven. Men der Bjørneboe diskuterer, der analyserer Koestler. Han var i mange år relativt tett på forskningsfronten i nevrovitenskap relatert til emosjoner og tenking. Som autodidakt og uten klinisk hverdagserfaring lå styrken og verdien av hans formidling fortrinnsvis i formuleringskraften og bilde- bruken, men han formulerte også hypoteser av direkte nevrovitenskapelig relevans, som for eksempel hypotesen om hjernens holistiske oppbygning $(18,20)$.

Kan man summere opp Koestlers nevrolitterære arv eller hans hypoteser? Sannsynligvis ikke. Til det hadde han en for omfattende og spennende produksjon. Hans gode faglige innsikt i nevrologiske og nevropsykologiske emner ble viet oppmerksomhet på hans 70-årsdag, bl.a. av Paul MacLean $(27,30)$.

Jeg mener han fortjener en plass i nevrolitteraturen, og flere av hans bøker tåler å bli lest også i dag. Hans kunnskap og hypoteser om hjernens utvikling og oppbygging samt tolking av hvorledes totalitær tankegang oppstår, er relevant medisinskhistorisk kunnskap. Han er overraskende aktuell, noe blant annet referansene til ham i Hagtvedts bokkapittel viser (15). Fjorårets biografi demonstrerer også hans aktualitet (7). Biografien er dessverre ikke sterk på analyse av innhold i Koestlers litterære produksjon og beskriver best det politiske og sosialt krevende mennesket. Således ville det, etter denne introduksjonen av Koestler, være interessant med utfyllende analyser av hans nevrolitterære hovedverker (16-18).

\section{Bernt A. Engelsen (f. 1951)}

er overlege, professor i nevrologi og leder av Epilepsienheten. Han er også medlem

i Den norske nevrolitterære klubb.

Forfatter har fylt ut ICMJE-skjemaet og oppgir ingen interessekonflikter.

\section{Litteratur}

1. Koestler A. En pil i det blå. Oslo: Gyldendal Norsk Forlag, 1953

2. Koestler A. Den usynlige skrift. Oslo: Gyldendal Norsk Forlag, 1954

3. Koestler A. Ein spanisches Testament. Aufzeichnungen aus dem Burgerkrieg. Berlin: Fischer Taschenbuch Verlag, 1980

4. Koestler A. Jordens berme. Oslo: Gyldendal Norsk Forlag, 1948.

5. Koestler A. Ankomst og avreise. Oslo: Gyldendal Norsk Forlag, 1946

6. Koestler A. Mørke midt på dagen. Oslo: Gyldendal Norsk Forlag, 1948

7. Scammel M. Koestler. The indispensable intellectual. London: Faber and Faber, 2011.

8. Braatøy T. Arthur Koestler og psykoanalysen. Oslo: Cappelens Forlag, 1947

9. Koestler A, Koestler C. Strangers on the square. London: Abacus, 1984.

10. Koestler A. Yogien og kommisæren. Oslo: Gyldendal Norsk Forlag, 1946.

11. Koestler A. Lengselens tid. Oslo: Gyldendal Norsk Forlag, 1951.

12. Koestler A. Lotusen og roboten. Oslo: Gyldendal Norsk Forlag, 1960

13. Koestler A. Die Nachtwandler (Die Entstehungs geschichte unserer Welterkentnis). Bern: Suhrkamp Taschenbuch, 1980

14. Sørensen $\emptyset$. Hagtvet B. Steine BA, red. Ideologi og terrorisme. Totalitære ideer og regimer. Oslo: Dreyers Forlag, 2011.

15. Hagtvedt B. Den fascinerende fascismen. I: Sørensen $\varnothing$. Hagtvet B, Steine BA, red. Ideologi og terrorisme. Totalitære ideer og regimer. Oslo: Dreyers Forlag, 2011: 116-60.
16. Koestler A. Insight and outlook. London: MacMillan and Co, 1949

17. Koestler A. The Act of creation. London: Picador, 1964

18. Koestler A. The ghost in the machine. London: Picador, 1967

19. Koestler A. The roots of coincidence. London: Picador, 1972.

20. Koestler A. Janus: a summing up. London: Picador, 1978.

21. Koestler A. Bricks to Babel. London: Picador 1980

22. Koestler A. Der Krötenküsser. Der Fall des Biologen Paul Kammerer. Wien: Verlag Fritz Molden, 1971

23. Koestler A. The call girls. New York, NY: Random House, 1973

24. MacLEAN PD. Psychosomatic disease and the visceral brain; recent developments bearing on the Papez theory of emotion. Psychosom Med 1949; 11: 338-53

25. MacLean PD. Some psychiatric implications of physiological studies on frontotemporal portion of limbic system (visceral brain). Electroencephalogr Clin Neurophysiol 1952; 4: 407-18.

26. MacLean PD. The limbic system and its hippocampal formation; studies in animals and their possible application to man. J Neurosurg 1954: 11:29-44

27. MacLean PD. The imitative-creative interplay of our three mentalities. I: Harris H, red. Astride the two cultures. London: Hutchinsons, 1975: $187-211$

28. Papez JW. A proposed mechanism of emotion. Arch Neurol Psychiatry 1937; 38: 725-43.

29. Bard P. Central nervous mechanisms for emotional behavior patterns in animals. Research Publications of the Association for Research in Nervous \& Mental Disease 1939; 19: 190-218.

30. Harris $\mathrm{H}$, red. Astride the two cultures. London: Hutchinsons, 1975.

Mottatt 3.11. 2011, første revisjon innsendt 27.6 2012, godkjent 13.9. 2012. Medisinsk redaktør Merete Kile Holtermann. 